\title{
SECONDARY WAVE CREST FORMATION
}

\author{
By Kiyoshi Horikawä, C.E. Member
}

Synopsis : The critical condition for the formation of secondary wave crests in shallow water has been studied using a wave channel $3 \mathrm{ft}$. deep by $1 \mathrm{ft}$. wide by $60 \mathrm{ft}$. long. In the preliminary experiment a horizontal model reef with a vertical drop at its seaward end was installed in order to extend the results of Mason and Keulegan. In later tests this model reef was taken out and the experiment was conducted for a horizontal bottom extending over the entire length of wave channel. The theoretical criterion introduced by Miche was found to be a fairly reliable index.

\section{INTRODUCTION}

The formation of multiple waves has been recognized both in the field ${ }^{13}$ and in the laboratory ${ }^{2,3,4,5,6)}$ especially when the waves move over bottom discontinuities, and seems to play an important role in the wave phenomena.

Mason and Keulegan ${ }^{4}$ studied experimentally the wave velocity method for determining depths over bottom discontinuities, and observed the deformation of waves in the shallow water over a reef. Barbe and Beaudevin ${ }^{2}$ observed the formation of multiple crest when waves moved over a model rubble mound breakwater before the breakwater was close enough to the surface to cause the waves to break. Recently Wiegel and Arnold ${ }^{6)}$ observed these multiple waves in their process of the experiment concerning the wave refraction and reported their conclusion as follows: "It appeared that the formation of multiple wave crests was associated to some extent with the combinations of parameters for which Snell's law became inaccurate in predicting the refracted wave angle at all times'. From this point of view we have continued this study for investigating the characteristics of multiple waves.

As the formation of these waves originally had been assumed to be based on the rapid change in the water depth, the first series of tests were conducted using a model reef with a vertical face. However, the formation of secondary crests was observed in water seaward of the reef for long waves and it became evident that at least one portion of the multiple crest formation was a characteristic of long waves. Hence in later tests the model reef was removed.

Miche $^{7)}$ introduced a theoretical criterion for the critical condition for the formation of a secondary crest at the wave trough. Comparison of the experimental data with the Miche's theory showed that his theory could be applied to explain the experimental results.

\section{REVIEW OF PREVIOUS RESULTS}

As stated in the introduction results have been obtained in previous studies of the formation of multiple waves. They are reviewed herein.

a) Experimental Study by Mason and Keulegan: Mason and Keulegan ${ }^{4}$ used the three types of bottom configuration shown in Fig. 1 to obtain the data for determining the water depth over the bottom discontinuities.

(a) An abrupt discontinuity followed to shoreward by a horizontal shelf at constant depth. (Fig. 1 a)

(b) An abrupt discontinuity followed to shoreward by a uniformly shoaling bottom. (Fig. $1 \mathrm{~b}$ )

(c) An abrupt discontinuity followed by a horizontal shelf, a depression, and a continuation of the horizontal shelf, in order. (Fig. 1 c)

The experimental data obtained were plotted on a graph of $\frac{H_{2}}{2 d_{2}} / \frac{L_{2}}{L_{1}}$ vs. $\sqrt{\frac{H_{1} L_{1}}{2}} / d_{2} * *$, where $H_{2}$,

* Assistant Professor of Civil Engineering, University of Tokyo

** For convenience the notations were changed from those in the original paper. 
$L_{2}$ and $H_{1}, L_{1}$ are the wave height and the wave length over the reef and in deep water, respectively, and $d_{2}$ is the water depth over the reef. The points plotted on the graph had different marks for each wave characteristic: (1) regular, (2) deformation, and (3) break and deformation (Fig. 2). The fol-

Fig. 1 Schematic View of Reef and Wave Apparatus (after Mason and Keulegan, 1944)

a.

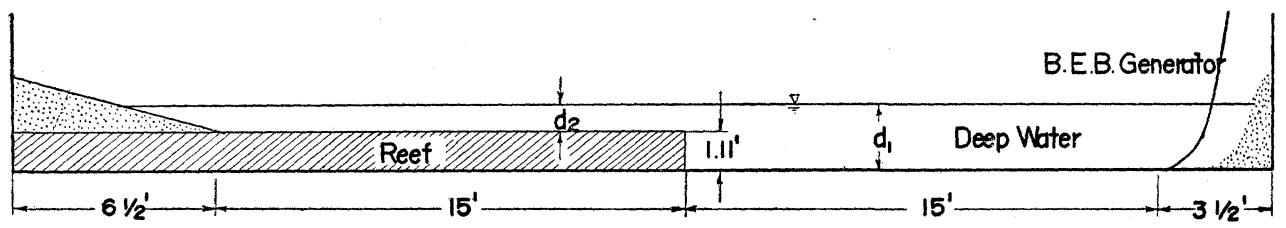

b.

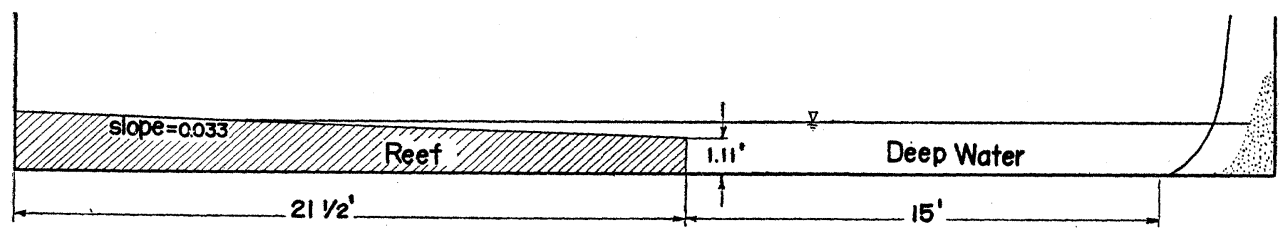

c.

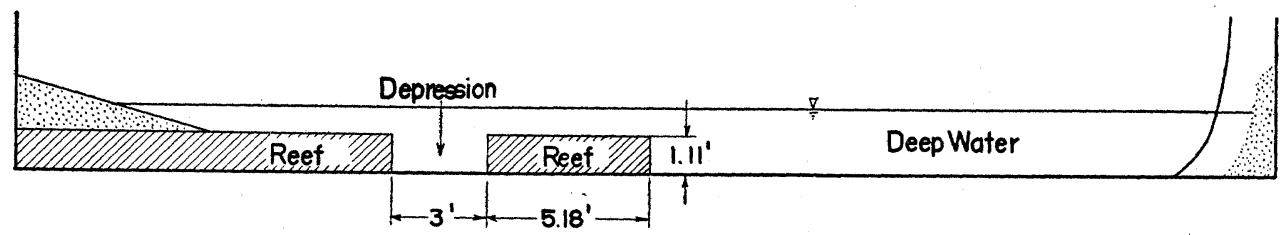

Fig. 2 Criterion of Regular Transition. (after Mason and Keulegan, 1944)

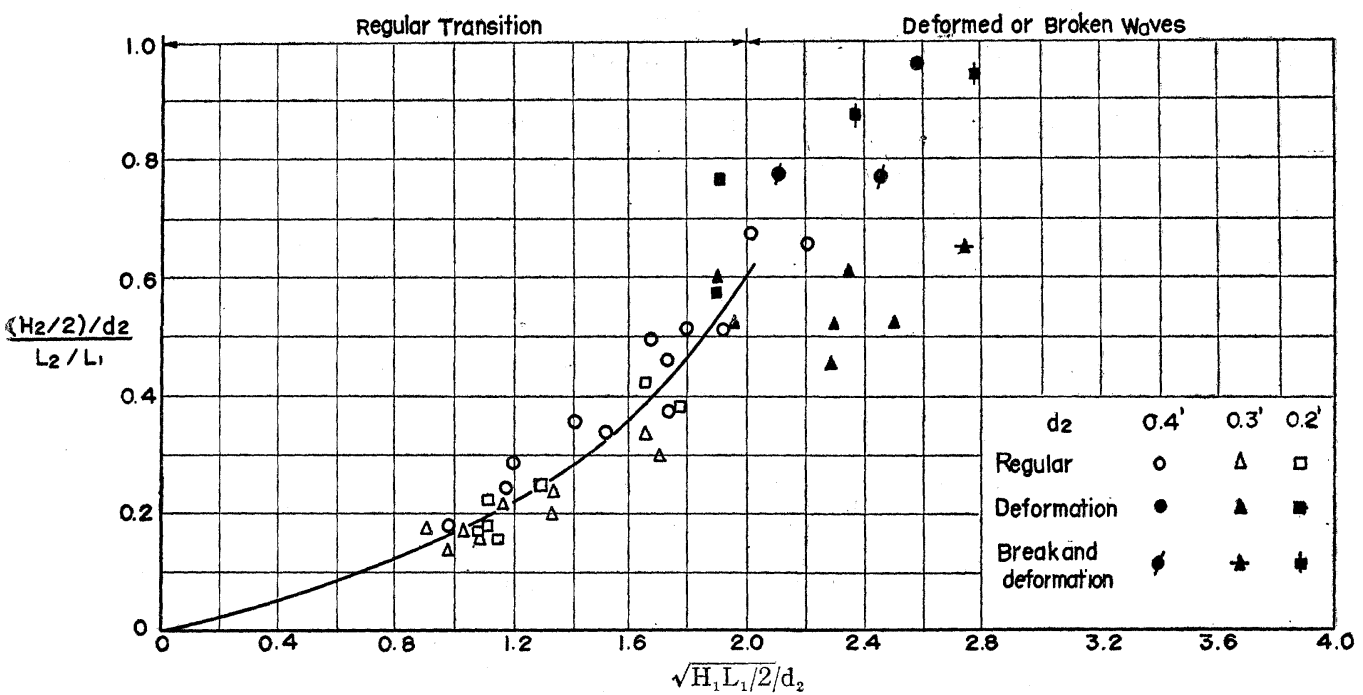

lowing equation was established as the criterion for the formation of multiple waves; that is,

$$
\sqrt{\frac{H_{1}}{L_{1}}}=2^{\frac{3}{2}} \cdot \frac{d_{2}}{L_{1}} \text {. }
$$

The above result shows that the wave which satisfies the condition of $\sqrt{\frac{H_{1}}{L_{1}}}<2^{\frac{3}{2}} \cdot \frac{d_{2}}{L_{1}}$ will be regular. Mason and Keulegan say, "This condition is used for the case in which the level of the troughs of the incoming waves is higher than the level of the reef (bottom). When the level of the troughs is below the level of the reef (bottom), the transition of waves becomes regular once more." 
b) Experimental Study by Wiegel and Arnold: The refraction of uniform periodic water waves over a submerged shoal of constant slope with straight parallel contours (slopes ranging from 1:10.6 to vertical) has been studied and was vertified as following Snell's law. ${ }^{6)}$ However, under some conditions multiple crested waves were formed and seemed to be associated in some manner with the inaccurate prediction of the refracted wave angle by use of Snell's law.

The author tried to find the reason why such multiple waves appeared in the non-linearity of the wave motion and cited as one measure the relation,

$$
H \ll \frac{32 \pi^{2} d^{3}}{3 L^{2}}
$$

which was introduced by Longuet-Higgins ${ }^{8)}$ as a criterion for the applicability of the linear wave theory.

c) Theoretical Study by Miche: The following equations were developed by Miche as the 2nd order approximation of wave motion $^{7}$;

$$
\begin{aligned}
x= & x_{0}+\frac{a \cosh \frac{2 \pi}{L}\left(d-y_{0}\right) \cdot \sin \left(\frac{2 \pi}{T} t-\frac{2 \pi}{L} x_{0}\right)}{\sinh \frac{2 \pi d}{L}} \\
& -\frac{a^{2}}{4}\left(\frac{2 \pi}{L}\right) \frac{\sin 2\left(\frac{2 \pi}{T} t-\frac{2 \pi}{L} x_{0}\right)}{\sinh ^{2} \frac{2 \pi d}{L}}\left[1-\frac{3}{2} \frac{\cosh \frac{4 \pi}{L}\left(d-y_{0}\right)}{\sinh ^{2} \frac{2 \pi d}{L}}\right]+a^{2} \nu\left(y_{0}\right) \cdot t, \\
y= & y_{0}-\frac{a \sinh \frac{2 \pi}{L}\left(d-y_{0}\right) \cdot \cos \left(\frac{2 \pi}{T} t-\frac{2 \pi}{L} x_{0}\right)}{\sinh \frac{2 \pi d}{L}} \\
& -\frac{a^{2}}{4}\left(\frac{2 \pi}{L}\right) \frac{\sinh ^{\frac{4 \pi}{L}}\left(d-y_{0}\right)}{\sinh ^{2} \frac{2 \pi d}{L}}\left[1+\frac{3}{2} \frac{\cos 2\left(-\frac{2 \pi}{T} t-\frac{2 \pi}{L} x_{0}\right)}{\sinh ^{2} \frac{2 \pi d}{L}}\right],
\end{aligned}
$$

in which $x$ and $y$ are the horizontal and vertical coordinates. The positive direction of $x$ axis is taken from left to right, and the positive direction of $y$ axis downward. $x_{0}$ and $y_{0}$ are coordinates of particles at rest and $y_{0}=0$ is the surface of the water at rest. $T, L, d$, and $a$ are the wave period, wave length, water depth and wave amplitude, respectively.

Beyond some condition the wave profile is deformed as shown in Fig. 3. Therefore, the critical

Fig. 3 Form of Free Surface of a Wave with Secondary Crest.

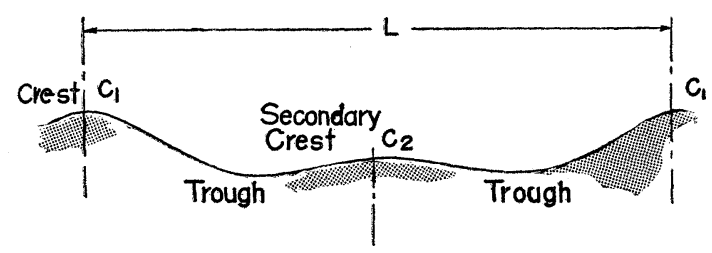

condition is expressed by the following equation, which means that the camber of the free surface at: the point $\mathrm{C}_{2}$ (trough) becomes null.

$$
\frac{\partial^{2} y}{\partial x_{0}{ }^{2}}=a\left(\frac{2 \pi}{L}\right)^{2} \frac{\sinh \frac{2 \pi}{L}\left(d-y_{0}\right)}{\sinh \frac{2 \pi d}{L}} \cdot \cos \left(\frac{2 \pi}{T} t-\frac{2 \pi}{L} x_{0}\right)+a^{2}\left(\frac{2 \pi}{L}\right)^{3} \frac{3}{2} \frac{\sinh \frac{4 \pi}{L}\left(d-y_{0}\right)}{\sinh ^{4} \frac{2 \pi d}{L}} \cdot \cos 2\left(\frac{2 \pi}{T} t-\frac{2 \pi}{L} x_{0}\right)
$$

at the point $\quad y_{0}=0$, and $x_{0}=\frac{L}{T} t-\frac{L}{2}$.

Hence, $\quad \delta_{\text {critical }}=\frac{2 a}{L}=\frac{1}{3 \pi} \sinh ^{2}\left(\frac{2 \pi d}{L}\right) \cdot \tanh \left(\frac{2 \pi d}{L}\right)$. 


\section{EXPERIMENTAL PROCEDURE AND EQUIPMENT}

When this experimental study was initiated, it was believed that the generation of the undulation on the wave profile might be due to the abrupt discontinuity of water depth. Therefore in the preliminary experiment a horizontal model reef with a vertical seaward face $(0.552 \mathrm{ft}$. high $)$ was installed in a wave channel, $1 \mathrm{ft}$. wide, $3 \mathrm{ft}$. deep, and $60 \mathrm{ft}$. long. (Fig. $4 \mathrm{a}$ ) The water depth of the deeper

Fig. 4 Laboratory Equipment.

a.

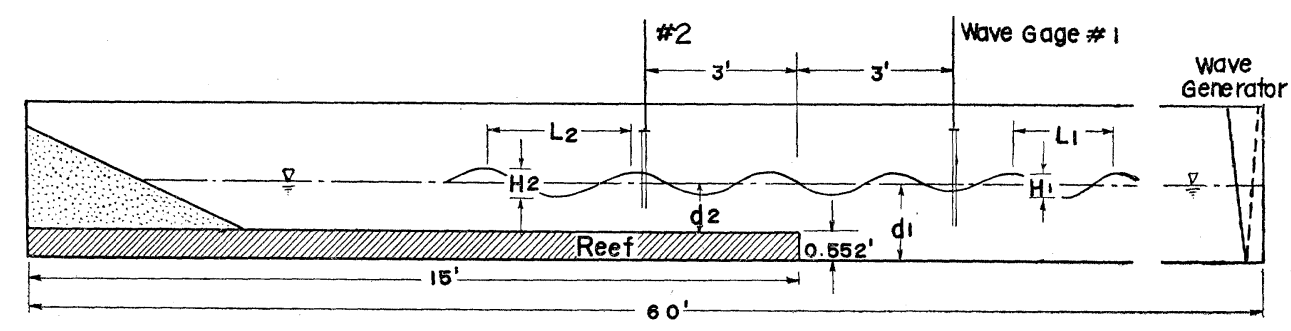

b.

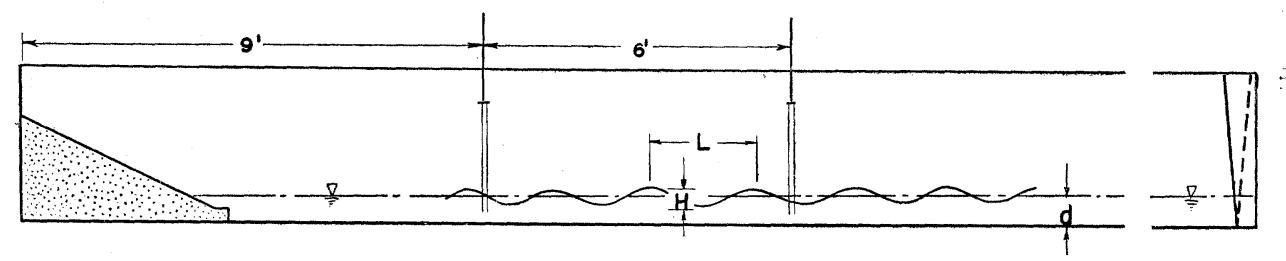

part, $d_{1}$ was held constant at $0.750,1.000 .1 .250$, and $1.5000 \mathrm{ft}$., with the water depth over the reef, $d_{2}$, being $0.198,0.488,0.698$, and $0.948 \mathrm{ft}$, respectively. Wave periods of $0.6,0.8,1.0,1.2,1.4,1.6$, 1.8 and $2.0 \mathrm{sec}$. and wave heights in the deeper part between 0.02 and $0.44 \mathrm{ft}$. were used. Two parallel wire resistance wave gages were used to record the wave characteristics, one was used to measure the waves in the deeper part of the channel and the other was used to measure the waves over the reef. The wave records in the deeper part were obtained prior to the time that the waves reflected from the vertical face of the reef returned to the wave recorder. These records were used to obtain the incident wave characteristics.

In the second series of experiments the model reef was taken out, leaving the bottom of wave channel horizontal so that the water was of uniform depth. Water depths, $d$, of $0.198,0.448$, and $0.698 \mathrm{ft}$. were used together with the same wave characteristics used in the first set of tests. Two wave gages were installed along the wave channel six feet apart. By use of the records from these two gages it was possible to compare them so as to distinguish between the effects of wave reflection and the formation of the secondary wave crests (Fig. $4 \mathrm{~b}$ ).

\section{EXPERIMENTAL RESULTS AND DISCUSSION}

The fundamental elements which govern the wave characteristics are (1) wave period, $T,(2)$ wave length, $L$, (3) wave celerity, $C$, (4) wave height, $H$, and (5) water depth, $d$.

These factors are not all independent but are inter-related by the following formulae,

$$
\begin{aligned}
& L_{0}=\frac{g}{2 \pi} T^{2}, \quad C_{0}=\frac{g}{2 \pi} T, \\
& L=L_{0} \tanh \frac{2 \pi d}{L}, \quad C=\sqrt{\frac{g L}{2 \pi} \tanh \frac{2 \pi d}{L}}, \\
& \frac{H}{H_{0}}=\sqrt{\frac{1}{2} \cdot \frac{1}{n} \frac{C_{0}}{C}}, \quad n=\frac{1}{2}\left[1+\frac{4 \pi d}{L} / \sinh \left(\frac{4 \pi d}{L}\right)\right],
\end{aligned}
$$

where the subscript $o$ refers to the characteristics of deep water waves. In dimensionless expressions the terms $d / L_{0}$ or $d / L$ and $H / L=\delta$ are used. 
When waves approach shore, the wave profiles are gradually deformed due to the decrease of water depth. The waves usually ultimately break to become irregular undulations with highly developed turbulence. In regard to these undulations there has not yet been any clear theoretical treatment except Sato's ${ }^{9)}$ and Ijima's ${ }^{10)}$ approaches.

The undulations of the wave profiles should be limited by the critical condition for breaking. Miche $^{7)}$ gives the following equation as the limiting steepness for progressive Stokes' waves in water of finite depth;

$$
\left(\frac{H}{L}\right)_{\max }=0.142 \tanh \frac{2 \pi d}{L}
$$

The data of Danel $^{11)}$ and $\mathrm{Hamada}^{12)}$ prove that the above relation is satisfactory from the practical point of view. Combining Eq. 7 with the equation,

$$
\frac{d}{L_{0}}=\frac{d}{L} \tanh \frac{2 \pi d}{L},
$$

the critical steepness $\delta_{\max }$ may be expressed as a function of $d / L_{0}$ (Fig. 5).

Fig. 5 Critical Wave Steepness.

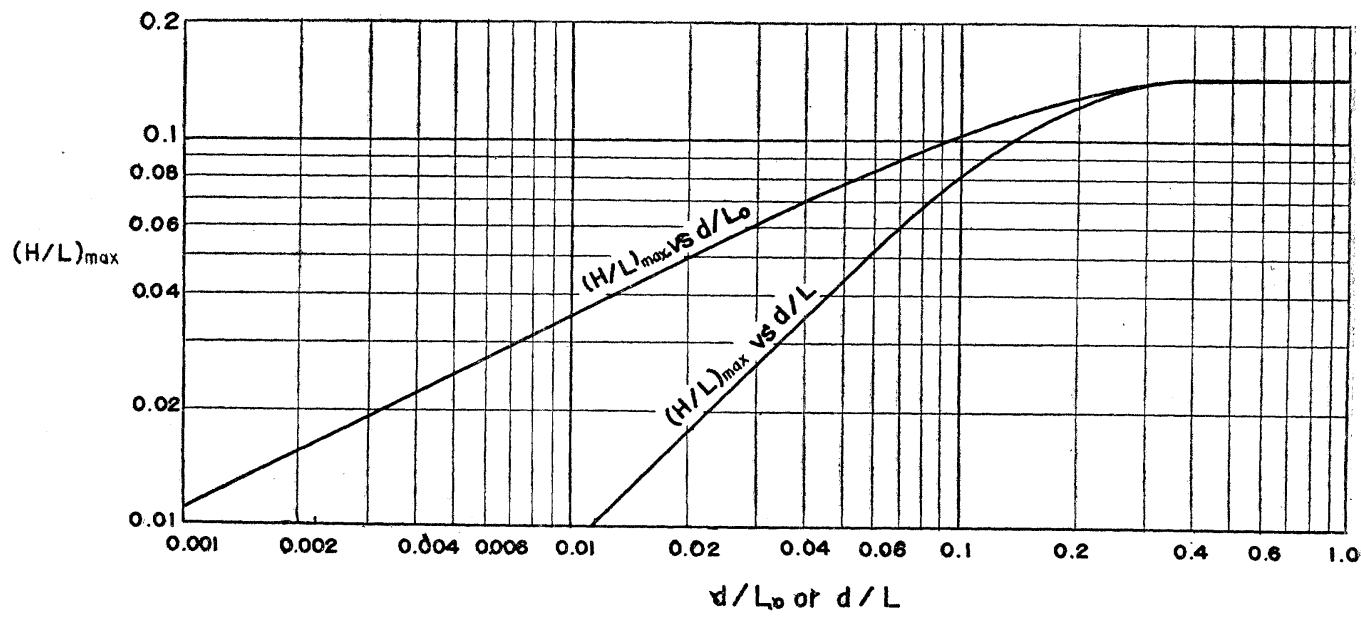

(a) Results of the First Set of Tests : To investigate the relationship obtained by Mason and Keulegan, the data obtained in the first series of experiments (see Fig. $\mathbf{6}$ for a sample record) were plotted as.

Fig. 6 Wave Records (First Set of Tests) $d_{1}=1.25$ feet, $T=1.80 \mathrm{sec}$

Gage $\# 2, \mathrm{H}_{2}=0.149^{\prime}$
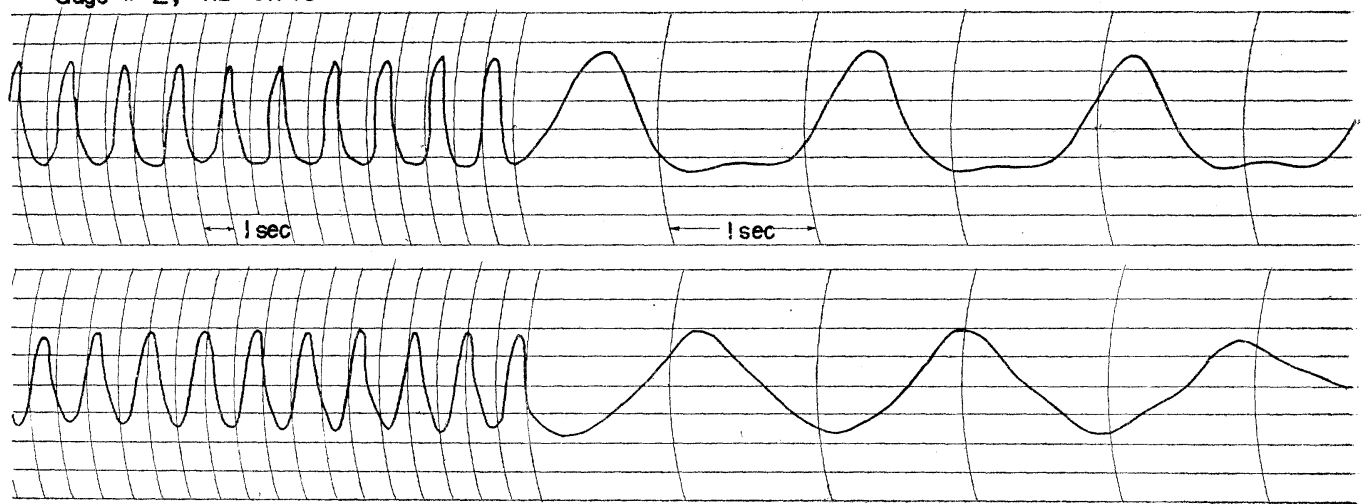

Gage $1, \quad H_{1}=0.161^{\prime}$

$H_{1} / L_{1}$ vs. $d_{2} / d_{1}$ in Fig. 7. Generally speaking the results show that Equation (1) is a fairly reliable index of the formation of multiple waves over a reef. However; a closer analysis of the data showed 

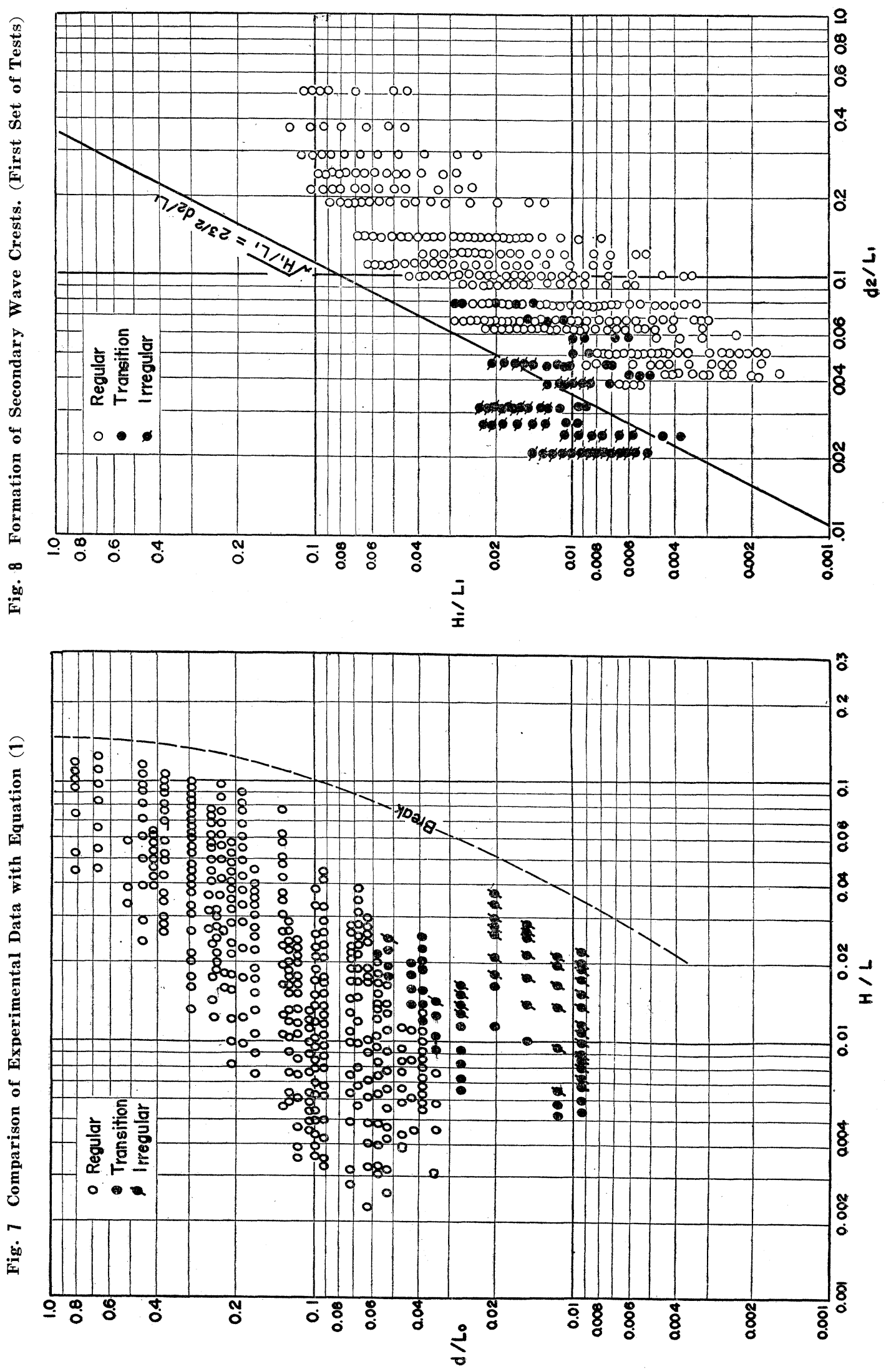
Fig. 9 Formation of Secondary Wave Crests. (Second Set of Tests)

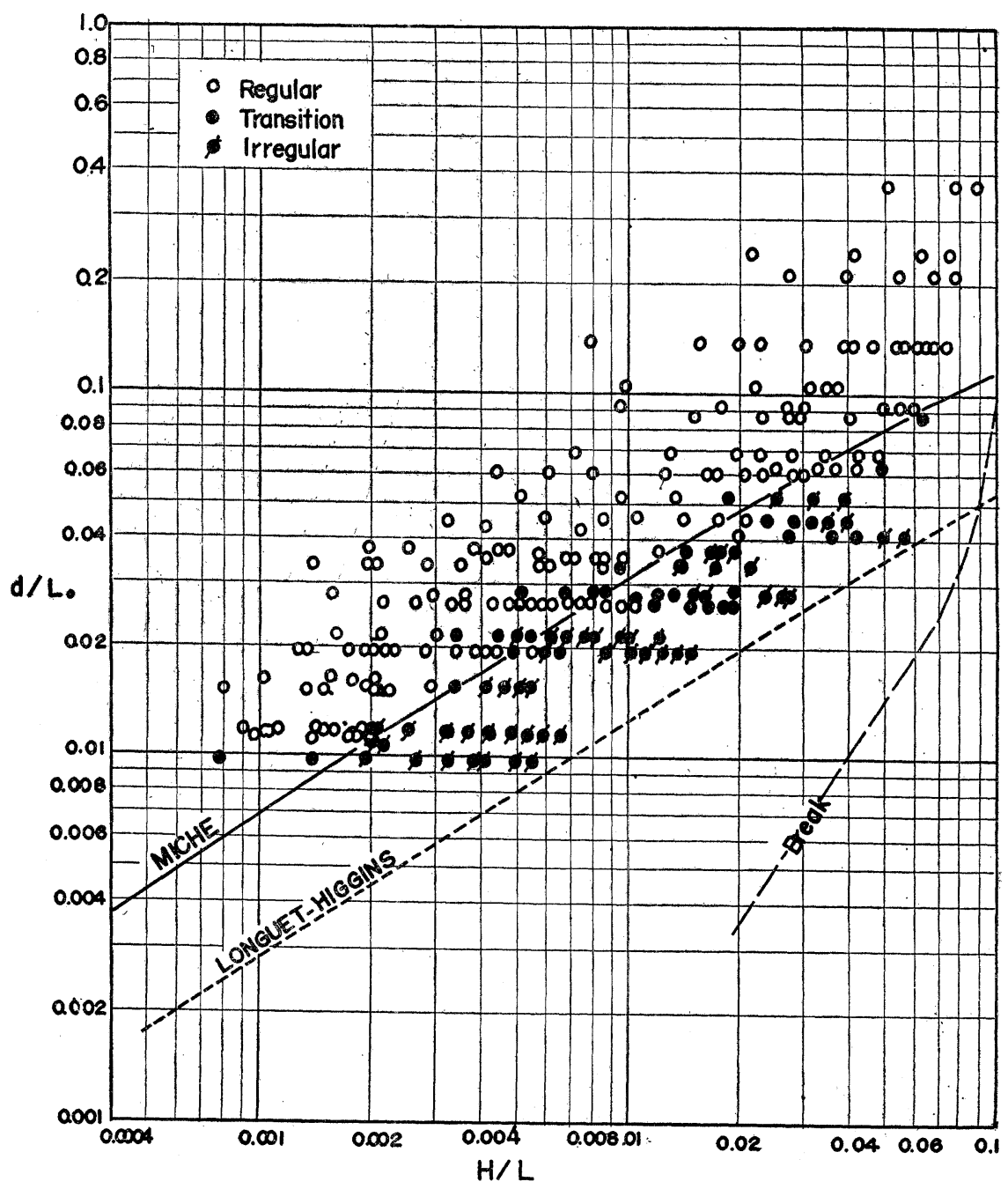

Fig. 10 Wave Records (Second Series of Tests)

$d=0.199$ feet, $T=1.4 \mathrm{sec}$., $H=0.0122$ feet

Gage \#1

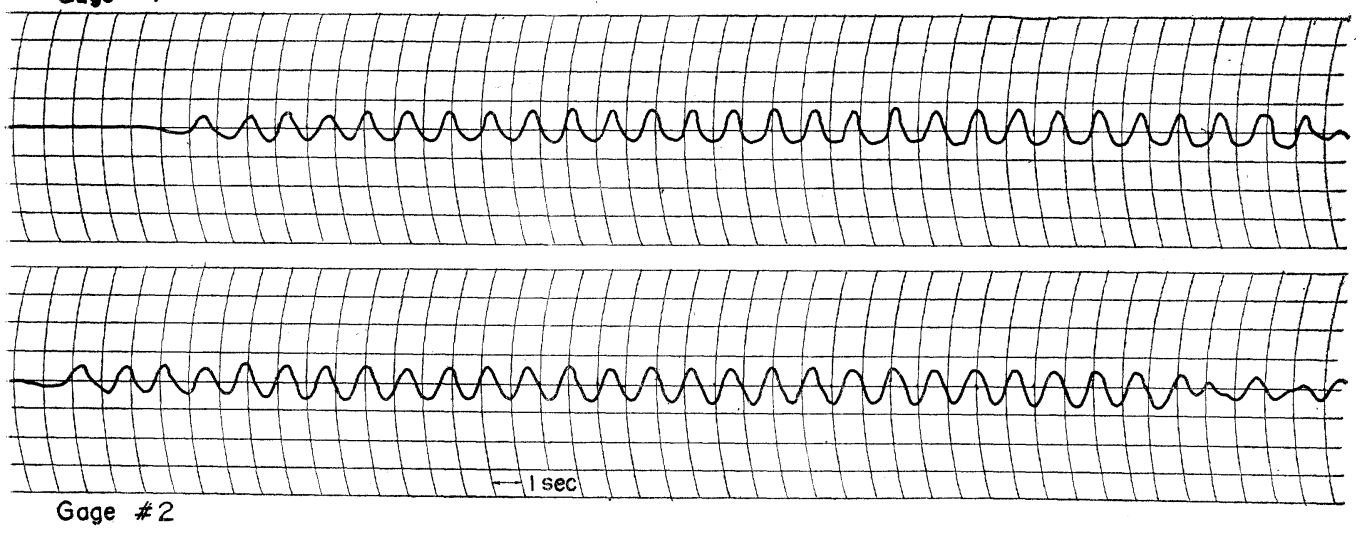


that there were several cases in which the secondary crests appeared even in the deeper part of the channel. That is, the formation of the secondary crests seemed to be one of the fundamental characteristics of waves, rather than of the shape of the bottom. Fig. 8 was prepared to see whether the above observation was correct or not. In this figure the data obtained both in the deeper part and on the reef were analyzed separately and plotted on the same graph. However, there were not enough data obtained in the deeper part of the channel to accomplish this check.

(b) Results of the Second Set of Tests: The same procedure as outlined above was followed, resulting in Fig. 9. It was fairly difficult to distinguish the critical condition from the data (see Fig. 10 for an example); therefore, three different marks, that is clearly regular, clearly irregular and not definite, were used to represent the data. It can be seen that there exists a definite relationship between $H / L$ and $d / L_{0}$ with respect to the critical condition of the formation of secondary crests.

Equations (2), (5) and (8) are also plotted in Fig. 9. It is evident that Miche's theory is a good criterion from the engineering point of view. As the criterion of Longuet-Higgins is an inequality which expresses the fact that $\frac{H}{L} \ll \frac{32 \pi^{2}}{3}\left(\frac{d}{L}\right)^{3}$ it appears that it would approach Miche's criterion, and in this manner fix the degree of the inequality.

(c) Discussion: In this experiment a wave channel, $60 \mathrm{ft}$. long, with a flatter type wave generator was used, and the wave characteristics were recorded at two fixed points using parallel wire resistance wave gages. Most of the time, especially in the second set of tests, a wave filter was installed near the wave generator to reduce reflections and to reduce irregularities of the generated waves. These conditions are mentioned because of the following facts : (1) the characteristics of waves generated by mechanical devices might depend upon the type of wave generator used, and (2) the wave characteristics are gradually changed along the wave channel. The installation of wave filters may also cause some effect on the wave characteristics. It was evident in these tests that the waves deformed as they progressed along the wave channel, even in water of uniform depth. One of the reasons for the above observation is the effect of friction both of the side walls and of the bottom. A second reason may be based on the nonlinearity of some wave motion as shown theoretically by J.J. Stoker ${ }^{13)}$.

The criterion of Miche is obtained from the second order approximation of the wave profile. It would seem that the third, fourth order terms, etc., would become more important in regard to the wave deformation than in regard to the magnitude of the wave profile itself. An equation with higher order terms would probably allow a more accurate prediction of the formation of secondary crests. From these points of view the experimental results of Savage ${ }^{14)}$ is quite interesting. Savage recorded the wave profiles along one of the wave channels at Beach Erosion Board, and analyzed them by Fourier's method. According to his analysis the higher order terms gradually increased in magnitude, and finally seemed to approach to some constant value. The generated wave approximated a sine wave near the wave generator, but gradually changed its shape and finally became a wave with a secondary crest. This experiment was performed for one special case in shallow water. The accumulation of this kind of information is required to obtain a clear understanding of the deformation of wave profiles and on the required minimum length of a wave channel used for obtaining a steady wave condition.

\section{CONCLUSIONS}

1. The relationship given by Mason and Keulegan has been verified as being useful in the prediction of the formation of secondary waves over a reef with a vertical face.

2. The theoretical critical condition introduced by Miche predicts satisfactory experimental observations of secondary crest formation.

3. The formation of a secondary crest at the wave trough is a characteristic of the wave itself and the water depth rather than of the shape of the bottom. 
purely ideal conditions. It should therefore be added that they must be modified to some extent in the light of various controlling factors which are simultaneously present in an apparently irregular pattern. For instance, in conducting a series of experiments on the effect of a submerged breakwater ${ }^{15}$, the author has remarked that inshore of a submerged wall the incident wave would be separated into a group of small waves, mostly two, with the heights of a comparable magnitude. This fact seems to emphasize the necessity of introducing the knowledge of the secondary wave to evaluating the damping mechanism of a submerged breakwater. The author has also noticed in the course of field investigation that when a long swell undergoes a final breaking at the shoreline a secondary crest appears immediately ensuing the main crest which has just broken. The author is planning an investigation on the similar phenomena which occur under natural conditions involving the secondary wave.

\section{ACKNOWLEDGEMENTS}

This work represents a part of results of research carried out for the Beach Erosion Board, under contract with the University of California.

The author wishes to express his appreciation to Professor J.W. Johnson for his suggestions. He also wishes to thank Mr. R.L. Wiegel for his valuable assistance in reading the manuscript, Mr. A.L. Arnold for his great help in conducting the experiments and working on the experimental equipment, and Miss M.M. Lincoln for preparing the figures.

\section{REFERENCES}

1) Johnson, J.W., R.A. Fuchs, and J.R. Morison, The damping action of submerged breakwaters, Trans. A.G.U., Vol. 32, No. 5, Oct. 1951 .

2) Barbe, R. and C. Beaudevin, Recherches experimentales sur la stabilite d'une jetee a talus incline soumise a la houle, La Houille Blanche, Vol. 8, No. 3, pp 346-359, , 1953.

3) Chien, Ning, Ripple tank studies of wave refraction, Trans. A.G.U., Vol. 35, No. 6, Dec. 1954.

4) Mason, M.A., and G.H. Keulegan, A wave method for determining depths over bottom discontinuities, Beach Erosion Board, Technical Memo., No. 5, May 1944.

5) Ralls, G.C., Jr,. A ripple tank study of wave refraction, Journal of Waterways Division, Proc. A.S.C.E., Vol. 88, Paper 900, March 1956.

6) Wiegel, R.L., and A.L. Arnold, Model, study of wave refraction, Beach Erosion Board, Tech. Memo., No. 103, Dec. 1957.

7) Miche, M., Mouvements ondulatories de la mer en profondeur constante ou decroissante. Ann. des Ponts et Chausees, Tome 114, 1944, Miche, M., Undulatory movements of the sea in constant or decreasing depth.

Trans. by M.M. Lincoln. and R.R. Chevron, Univ. of Calif., Inst. of Engr. Res., Wave Research Lab., Series 3 , Issue 363 , Jane 1954 .

8) Longuet-Higgins, M.S., The refraction of sea waves in shallow water, Jour. Fluid Mechanics, Vol. 1, Part 2, July 1956.

9) Sato, S., On the sand drift, 4th Report, Shallow water surface waves, Report, Public works Research Inst., Vol. 82 , No. 5, Mar. 1952. (In Japanese)

10) Ijima, T., T. Takahashi, and K. Nakamura, Wave characteristics in the surf zone observed by stereographic camera, Proc. 3rd Conf. on Coastal Engr., Japan, Nov. 1956. (In Japanese)

11) Danel, P., On the limiting clapotis, Gravity Waves, Nov. 1952

12) Hamada, T., Breakers and beach erosions, Rept. of Transportation Tech. Res. Inst., No. 1 , Dec. 1951.

13) Stoker, J.J., The formation of breakers and bores. Communications on Applied Mathematics, Vol. 1 , No. 1, 1948. Stoker, J.J. Water Waves, 1957.

14) Savage, R.P., Personal Communication, Beach Erosion Board, Corps of Engineers, U.S. Army, Oct. 1958.

15) Horikawa, K., and C. Sonu, Experimental study on a submerged breakwater, Abstract of Papers, 12th Annual Meeting, J.S.C.E., June 1957. (In Japanese) 